\title{
ACOSO MORAL EN EL TRABAJO: DE SU CONSTRUCCIÓN JURISPRUDENCIAL A UNA NECESARIA REGULACIÓN LEGAL
}

\author{
Macarena Ángel Quiroga \\ Departamento de Derecho del Trabajo \\ y de la Seguridad Social \\ Facultad de Derecho \\ Universidad Complutense de Madrid \\ macangel@ucm.es
}

\section{INTRODUCCIÓN}

El objetivo principal de esta investigación consiste en estudiar el problema del mobbing desde la perspectiva del Derecho del Trabajo con el fin de encontrar una solución jurídica que proteja de manera eficaz a todas las víctimas del mismo.

El acoso moral en el trabajo es una realidad en un gran número de empresas, un problema que ha existido a lo largo de la historia y que continúa sin una respuesta legal clara al respecto.

Las consecuencias del mobbing son demoledoras para las víctimas del mismo, tanto para su salud física y mental como para su rendimiento laboral y productividad. Asimismo, supone un perjuicio para toda la sociedad no solo por ser una conducta destructiva para el ambiente de trabajo de la empresa, sino también por el grave impacto económico que conlleva para las arcas de la Seguridad Social.

Según la Quinta Encuesta Europea sobre las Condiciones de Trabajo, publicada en 2010 por el Eurofound, el 4,1 por 100 de los trabajadores europeos se quejaron de haber sido objeto de intimidaciones o de acoso moral en el trabajo ${ }^{1}$. Asimismo, según la Sexta Encuesta Europea sobre las Condiciones de Trabajo de $2015^{2}$, el 10 por 100 de los españoles afirmó

${ }^{1}$ https://www.eurofound.europa.eu/es/surveys/european-working-conditions-surveys/fifth -european-working-conditions-survey-2010.

2 https://www.eurofound.europa.eu/es/data/european-working-conditions-survey. 
haber sido sujeto de una conducta social adversa; porcentaje que se eleva al 20 por 100 en Reino Unido, al 21 por 100 en Suecia, al 24 por 100 en Francia y al 27 por 100 en Países Bajos, entre otros.

\section{ORÍGENES}

Esta materia comenzó siendo estudiada por expertos en psicología, psiquiatría y sociología mucho antes de que se planteara como un problema de índole jurídica. También fue denunciado por personal sanitario, que cada vez observaba con mayor frecuencia los efectos que producía en la salud un ambiente de trabajo hostil.

Para poder entender en profundidad la cuestión objeto de estudio resulta necesario remontarse a esos orígenes del estudio del acoso moral en el trabajo.

El primer autor que utilizó el término de mobbing 3 fue Konrad Lorenz $z^{4}$, investigador austríaco que, desde la etología, lo definió como el ataque de una coalición de miembros débiles de una misma especie contra un individuo más fuerte que ellos 5 .

A principios de los años setenta se utilizó el término mobbing por el médico sueco Peter-Paul Heinemann refiriéndose a conductas hostiles que presentaban algunos niños en la escuela con respecto de otros, y en 1976, el psiquiatra estadounidense Carrol M. Brodsky publicó El trabajador hostigado, centrando ya el mobbing como un acoso sufrido por los trabajadores, describiendo cinco tipos de acoso: acoso sexual, designación de un chivo expiatorio, uso de motes desagradables, violencia física y presión en el trabajo ${ }^{6}$.

Sin embargo, el principal autor en la materia es Heinz Leymann, psicólogo de profesión, que proporciona una definición de mobbing como el

${ }^{3}$ El término anglosajón mobbing procede del verbo to mob, cuyo significado puede traducirse como «maltratar, atacar, asediar por un grupo». Asimismo puede traducirse como muchedumbre o multitud.

${ }^{4}$ G. Martínez Atienza, Tratamiento jurídico-criminológico del mobbing o acoso laboral, Barcelona, Vlex, 2011, p. 27.

5 Acotó dicho término tras estudiar el comportamiento agresivo de un grupo de cuervos contra uno mayor y solitario, un búho, acosándolo hasta que abandonó su zona de caza. $\mathrm{El}$ ataque era indirecto (evitando un ataque frontal con serias consecuencias para los cuervos intervinientes en la batalla), de hostigamiento sistemático cuyo resultado era el agotamiento del búho, que terminaba marchándose voluntariamente.

${ }^{6}$ M. F. Hirigoyen, Todo lo que hay que saber sobre el acoso moral en el trabajo, Barcelona, Paidós Contextos, 2014, p. 16. 
fenómeno o situación en que una persona o grupo de personas ejerce una violencia psicológica extrema, de forma sistemática y recurrente, durante un tiempo prolongado, sobre una persona en el lugar de trabajo, con la finalidad de destruir las redes de comunicación de la víctima o víctimas, destruir su reputación, perturbar el ejercicio de sus labores y lograr finalmente que esa persona o personas acaben abandonando el lugar de tra$\mathrm{bajo}^{7}$. Este autor, junto con la mayoría de los investigadores alemanes y escandinavos, atribuyó el origen del acoso a factores organizacionales de la empresa (una gestión empresarial favorecedora del mobbing) ${ }^{8}$.

Actualmente, Marie-France Hirigoyen, una de las mayores expertas en la materia, aporta su propia definición del acoso moral en el trabajo ${ }^{9}$ como toda conducta abusiva (gestos, palabras, comportamientos, actitudes) que atenta, por su repetición o su sistematización, contra la dignidad o la integridad física o psicológica de un trabajador y que pone en peligro su empleo o degrada el ambiente de trabajo ${ }^{10}$. Gracias a su obra se introdujeron en el Código de Trabajo francés los arts. L1152-1 a L1152-6, que regulan el acoso moral en el lugar de trabajo.

De estas definiciones podemos extraer una serie de notas características —que explicaremos más adelante en el apartado correspondiente- que son las siguientes: 1) conductas hostiles, 2) frecuencia o reiteración durante un periodo de tiempo, 3) relación asimétrica de poder y 4) intencionalidad.

Además del establecimiento de estas características esenciales del acoso, podemos destacar del trabajo de estos autores su percepción del origen del acoso, enfocándolo algunos de ellos en la empresa y otros en la personalidad del sujeto acosador.

Los primeros encuentran el germen del acoso en los factores organizacionales de la empresa. No puede producirse una situación de mobbing sin una empresa detrás que lo respalde o consienta. Se trataría de unos tipos

7 F. CAvas Martínez, «Un nuevo supuesto de extinción causal del contrato de trabajo por acoso laboral», Revista Doctrinal Aranzadi Social, párr. 38, vol. 6, núm. 5 (2013).

${ }^{8}$ En el mundo anglosajón, el estudio se centró más en las características individuales, así como en Francia, al añadir el adjetivo de «moral».

${ }^{9}$ En función del país, la conducta se conoce bajo un término u otro. En Francia se conoce como acoso moral (harcèlement moral au travail), incidiendo así en el sufrimiento moral que padece la víctima, mientras que en Reino Unido, Estados Unidos y algunos países del norte de Europa emplean el término bullying, que se refiere a agresiones insidiosas y perversas, y en el centro de Europa suele utilizarse mobbing, conservando una connotación más colectiva.

${ }_{10}$ M. F. Hirigoyen, Todo lo que bay que saber..., op. cit., p. 22. 
de gestión empresarial debilitadores de sus empleados en los que se ha ido modificando el ambiente de trabajo hasta resultar impersonal y automatizado. Los trabajadores apenas son informados de las decisiones estratégicas, que no pueden ser criticadas o contradichas. Se limita a la mínima expresión la opinión o sentir de los empleados que, de esta manera, ven imposible manifestar sus frustraciones o desacuerdos. Además, al producirse situaciones de acoso, faltas de respeto o humillaciones, la empresa no muestra una posición castigadora de las mismas, sino que las banaliza.

Pueden diferenciarse, según los autores escandinavos ${ }^{11}$, dos estilos de dirección que favorecen el acoso moral en el trabajo: el estilo autoritario y el pasivo. El primero de ellos se produce en organizaciones que favorecen el ascenso de miembros tiránicos en su escala jerárquica, que pasan por alto las necesidades de sus empleados y se caracterizan por una excesiva rigidez. El segundo tipo, al contrario que el primero, no tiene una organización bien definida y estable, las órdenes son imprecisas y se favorece así el acoso horizontal. Por su parte, Marie-France Hirigoyen incluye uno más, la dirección perversa, que considera a los trabajadores como recursos explotables mientras sean útiles y desechables cuando dejen de serlo. No se basa en ataques directos, sino sutiles y no evidentes.

En cuanto a las teorías que se centran en los sujetos acosadores, según Marie-France Hirigoyen, estos pueden comportarse de esta manera por miedo (de sus superiores, respecto de los cuales pueden sentirse también acosados), debilidad (al no saber hacer frente a sus problemas o responsabilidades focalizan su frustración en otro trabajador), falta de inteligencia emocional o competencias sociales, por necesidad de afirmarse (exceso o carencia de autoestima), por envidia o celos, o por pasividad (es más fácil unirse al grupo acosador que enfrentarse a él).

Asimismo, puede tratarse de personalidades patológicas, obsesivas, paranoicas o narcisistas.

Por su parte, las víctimas suelen ser personas que se rebelan o no aceptan el autoritarismo del acosador, resisten a sus presiones y no se dejan avasallar. Asimismo, son escrupulosas y perfeccionistas, desean cumplir rigurosamente con su trabajo. El acosador pretenderá mostrar al resto una imagen completamente diferente de la víctima, como una persona débil, afectada de algún tipo de patología, déspota e incumplidora de su trabajo.

${ }^{11}$ Ibid., p. 93. 


\section{NORMATIVA INTERNACIONAL, COMUNITARIA Y NACIONAL}

Tras analizar el estudio de la psicología, psiquiatría y sociología sobre el acoso moral en el trabajo, pasamos a referirnos al tratamiento normativo que se ha realizado sobre el mismo en el plano internacional, comunitario y nacional.

\section{Normativa internacional}

En el ámbito internacional no existe una regulación específica que obligue a los Estados a proteger a las víctimas de acoso moral en el trabajo. En lo que concierne a este trabajo, podemos mencionar los informes de la OIT, sin carácter vinculante, así como diferentes instrumentos que recogen los derechos que pueden verse vulnerados por una conducta acosadora.

Es el caso de la Carta Internacional de Derechos Humanos, compuesta a su vez por la Declaración Universal de Derechos Humanos; el Pacto Internacional de Derechos Económicos, Sociales y Culturales; el Pacto Internacional de Derechos Civiles y Políticos, y sus dos protocolos facultativos. De estos textos se extrae la defensa del derecho a la seguridad de la persona, a no verse sometido a actos inhumanos o degradantes y a no a ser objeto de ataques a su honra y reputación o molestado por razón de sus convicciones. Asimismo se recoge el derecho al trabajo y a que el mismo se desarrolle en unas condiciones equitativas y satisfactorias, y garantizando la seguridad de los trabajadores.

Por otra parte, existen diferentes convenios y protocolos de la OIT que, aunque no versan específicamente sobre el acoso moral en el trabajo, versan sobre materias relacionadas. Estos serían: Convenio OIT C-155, sobre seguridad y salud de los trabajadores (1981), junto con su Protocolo 155; Convenio OIT C-161, sobre los servicios de salud en el trabajo (1985), y Convenio OIT -187, sobre el marco promocional para la seguridad y salud en el trabajo (2006). Así como el Convenio Colectivo sobre prevención y solución de reclamaciones en materia de acoso entre la Oficina Internacional del Trabajo y el Sindicato de la OIT. 


\section{Normativa comunitaria}

En el ámbito de la Unión Europea se ha producido una importante variación en la forma de regular la materia de Seguridad y Salud en el Trabajo, ya que se ha pasado de optar por utilizar instrumentos vinculantes de obligatoria transposición, como son las directivas ${ }^{12}$, a instrumentos no vinculantes propios de la negociación colectiva en el ámbito comunitario. De esta manera, se redactaron dos Acuerdos Marco europeos relativos al estrés laboral y al acoso moral en el trabajo de fechas 2004 y 2007, respectivamente. De la aplicación del Acuerdo Marco europeo sobre estrés laboral en los diferentes países comunitarios se redactó en 2011 un Informe de la Comisión mucho más exhaustivo y detallado que el propio acuerdo. Explica que, a pesar de existir una mayor concienciación y un amplio consenso con respecto a la idea de que el estrés es un problema serio, la protección en Europa continúa siendo desigual, precisamente porque, mientras que algunos países han aplicado el Acuerdo a través de de leyes, normas o convenios vinculantes, en otros no se ha aplicado o se ha realizado a través de convenios o acuerdos no vinculantes en los que no todos los trabajadores se encuentran cubiertos. En lo que respecta a este trabajo, nos parece pertinente destacar la vinculación que estos instrumentos establecen entre el estrés y el acoso moral en el trabajo, pues ambos son considerados como riesgos psicosociales íntimamente relacionados con el diseño, organización y gestión del trabajo, así como su contexto económico y social.

Como comentábamos anteriormente, al no tratarse de instrumentos vinculantes como las directivas, su transposición no es obligatoria, sino que sigue las normas y prácticas de los sistemas nacionales de cada Estado miembro. De esta manera, no puede esperarse que los resultados sean

12 Vid. Directiva 89/391/CEE del Consejo, de 12 de junio de 1989, relativa a la aplicación de medidas para promover la mejora de la seguridad y salud de los trabajadores en el trabajo, y Directivas promotoras de la igualdad en el empleo tales como Directivas sobre la igualdad de trato entre hombres y mujeres, 2002/73/CE del Parlamento Europeo y del Consejo, de 23 de septiembre de 2002; 2004/113/CE del Consejo, de 13 de diciembre de 2004, y 2006/54/CE del Parlamento Europeo y del Consejo, de 5 de julio de 2006. También Directivas sobre la aplicación de la igualdad de trato de las personas con independencia de su origen racial, étnico, etc., como 2000/43/CE del Consejo, de 29 de junio de 2000, relativa a la aplicación del principio de igualdad de trato de las personas independientemente de su origen racial o étnico, y 2000/78/CE del Consejo, de 27 de noviembre de 2000, referente al establecimiento de un marco general para la igualdad de trato en el empleo y ocupación. 
los mismos que en el caso de regular estas conductas a través de directivas ni que la respuesta de los diferentes Estados sea idéntica. A pesar de ello, continua sin redactarse la tan esperada Directiva sobre acoso moral en el trabajo.

Por otra parte, el mobbing fue definido por el Comité Consultivo de Seguridad y Salud el 14 de mayo de 2001 como «un comportamiento negativo entre compañeros o entre superiores e inferiores jerárquicos, a causa del cual el afectado es objeto de acoso y ataques sistemáticos y durante mucho tiempo, de modo directo o indirecto, por parte de una o más personas, con el objetivo o el efecto de hacerle el vacío» ${ }^{13}$.

\section{Normativa nacional}

En nuestro país, la regulación legislativa en materia de acoso moral en el trabajo se ha desarrollado en el campo del Derecho penal. Con la reforma introducida por la Ley 5/2010, que entró en vigor el 23 de diciembre de 2010, se incluyó un segundo párrafo al art. 173.1 del Código Penal (CP) que tipifica, por primera vez en la historia de este Código, el delito de acoso laboral de la siguiente manera: «El que infligiera a otra persona un trato degradante, menoscabando gravemente su integridad moral, será castigado con la pena de prisión de seis meses a dos años. Con la misma pena serán castigados los que, en el ámbito de cualquier relación laboral o funcionarial y prevaliéndose de su relación de superioridad, realicen contra otro de forma reiterada actos hostiles o humillantes que, sin llegar a constituir trato degradan te, supongan grave acoso contra la víctima» ${ }^{14}$.

Los supuestos que se produjeron con anterioridad a la introducción del mencionado párrafo en el art. 173.1 deben ser resueltos conforme al CP

${ }_{13}$ Esta definición es recogida por diferentes sentencias, tales como SSTSJ de Galicia, Sala de lo Social, Sección 1. ${ }^{\text {, }}$, núm. 135/2012, de 23 de diciembre (AS/2012/85); Galicia, Sala de lo Social, Sección 1. ${ }^{\text {, }}$, núm. 5859/2010, de 17 de diciembre (AS/2011/97); Galicia, Sala de lo Social, Sección 1. ${ }^{a}$, núm. 5657/2010, de 7 de diciembre (AS/2011/148); Galicia, Sala de lo Social, Sección 1. ${ }^{a}$, núm. 386/2010, de 25 de enero (AS/2010/892); Islas Canarias, Sala de lo Social, Sección 1. ${ }^{a}$, núm. 726/2010, de 27 de mayo (AS/2010/2644); Madrid, Sala de lo Social, Sección 2. ${ }^{a}$, núm. 560/2014, de 23 de julio (AS/2014/2257), y Madrid, Sala de lo Social, Sección 2. ${ }^{a}$, núm. 105/2010, de 9 de febrero (AS 2010/1006), entre otras.

${ }^{14}$ Dicho precepto tan solo hace referencia al acoso laboral vertical y no al que pueda producirse entre compañeros de trabajo. Puede interpretarse, no obstante, que dicha situación de superioridad no tiene por qué predicarse solo de la jerarquía empresarial, sino que puede referirse a superioridad física o una mejor relación con el resto de compañeros de la empresa. 
anterior a la reforma ${ }^{15}$. Algunos tribunales consideran apropiado subsumir la conducta en el primer párrafo (y en aquel momento único) de ese precepto, mientras que otros entienden que eso suponía forzar el sentido del mismo. Dentro de la primera línea de actuación podemos mencionar la Sentencia de la Audiencia Provincial de Madrid, Sección 16. ${ }^{2}$, núm. 4/2010, de 29 de enero (ARP/2010/496) ${ }^{16}$ (contraria a la línea general de las Audiencias Provinciales), que afirma que el delito de acoso moral en el trabajo o mobbing es encuadrable en el apartado $1 .^{\circ}$ del art. $173 \mathrm{CP}$, en el que se castiga al que «infligiera a otra persona un trato degradante, menoscabando gravemente su integridad moral». Hace referencia, además, a diversas sentencias del Tribunal Supremo que recogen los requisitos que deben concurrir para que una conducta atente contra la integridad moral ${ }^{17}$. Como hemos advertido sobre estas líneas, las Audiencias Provinciales incardinan aquella línea contraria a lo recogido por el TS, considerando que el mobbing no tiene cabida en el art. 173.1 $\mathrm{CP}^{18}$ por forzar el tenor del mismo ${ }^{19}$.

En el campo del Derecho del Trabajo, sin embargo, no existe ninguna regulación legal específica en materia de acoso laboral.

15 Ana Isabel Pérez Machío entiende que los comportamientos degradantes y humillantes eran equiparables y podían quedar absorbidas por el original art. 173.1 CP, mientras que García Callejo subsume estas conductas en el art. 620.2 CP por no considerarlas de suficiente gravedad para ser integradas en el art. 173.1 CP. Vid. A. I. Pérez MaChío, Mobbing y Derecho penal, 1. ${ }^{\text {e }}$ ed., Valencia, Tirant lo Blanch, 2007, p. 145.

${ }_{16}$ Así como la STS, Sala de lo Penal, Sección 1. a , núm. 945/2010, de 28 de octubre (RJ/2010/8181).

17 SSTS, Sala de lo Penal, núm. 294/2003, de 16 de abril (RJ/2003/4381), y núm. 2101/2001, de 14 de noviembre (RJ 2002/1514).

${ }_{18} \mathrm{El}$ hecho de que se haya introducido un segundo párrafo al art. 173.1 CP ha servido para que muchas Audiencias Provinciales se reafirmen en su postura de que, con anterioridad al mismo, no cabía subsumir la conducta en el primer párrafo del art. 173.1 CP, en contra de la línea jurisprudencial de la Sala Segunda del Tribunal Supremo, que entendía oportuno castigar dichas conductas a través del mencionado artículo.

${ }_{19}$ Tales como la Sentencia de la Audiencia Provincial de Castellón, Sección 2. ${ }^{\text {, }}$, núm. 98/2014, de 14 de febrero (ARP/2014/554), según la cual afirman compartir el entendimiento de que el mobbing no debe subsumirse en el art. 173.1 CP (primer párrafo), en el que se tipifica el infligir a otra persona un trato degradante que menoscabe gravemente su integridad moral, ya que el hecho de que se hable de dicho «trato degradante» (que en los tratados internacionales suele referirse a términos como tortura, tratos crueles...) y que exija un menoscabo grave de la integridad moral lleva a pensar que las conductas del art. 173.1 CP contienen un plus de gravedad frente a lo que, por regla general, se conceptúa como acoso laboral. En esta misma línea vid. Sentencia de la Audiencia Provincial de Ourense, Sección 2. ${ }^{a}$, núm. 325/2015, de 25 de septiembre; Auto de la Audiencia Provincial de Madrid, Sección 17. ${ }^{\text {, }}$, núm. 122/2010, de 4 de febrero (JUR/2010/135458), y Auto de la Audiencia Provincial de Lleida, Sección 1. ${ }^{a}$, núm. 433/2008, de 12 de septiembre (JUR/2009/147658). 
De manera general, se recogen en el Estatuto de los Trabajadores ${ }^{20}$ algunos derechos que pueden verse vulnerados por el mobbing. Así, el art. 4, apartado 2.d), establece lo siguiente: «En la relación de trabajo, los trabajadores tienen derecho: a su integridad física y a una adecuada política de prevención de riesgos laborales». Asimismo, se señala en el apartado 2.e): «Los trabajadores tienen como derechos básicos, con el contenido y alcance que para cada uno de los mismos disponga su específica normativa, los de: [...] e) Al respeto de su intimidad y a la consideración debida a su dignidad, comprendida la protección frente al acoso por razón de origen racial o étnico, religión o convicciones, discapacidad, edad u orientación sexual, y frente al acoso sexual y al acoso por razón de sexo».

Este precepto debe ser puesto en relación con el art. 19.1 del mismo texto, que prevé el derecho del trabajador en la prestación de sus servicios a una protección eficaz en materia de seguridad y salud en el trabajo. De igual manera destaca el art. 20.3 del mismo cuerpo normativo, según el cual: «El empresario podrá adoptar las medidas que estime más oportunas de vigilancia y control para verificar el cumplimiento por el trabajador de sus obligaciones y deberes laborales, guardando en su adopción y aplicación la consideración debida a su dignidad y teniendo en cuenta, en su caso, la capacidad real de los trabajadores con discapacidad».

También el art. 8.11 del Real Decreto Legislativo 5/2000, de 4 de agosto, por el que se aprueba el Texto Refundido de la Ley sobre Infracciones y Sanciones en el Orden Social (LISOS), establece como infracción muy grave los actos del empresario que fueren contrarios al respeto de la intimidad y consideración debida a la dignidad de los trabajadores.

Igualmente, el art. 2 de la Ley 31/1995, de 8 de noviembre, de Prevención de Riesgos Laborales (LPRL), tiene por objeto promover la seguridad y salud de los trabajadores mediante la aplicación de determinadas medidas, así como el desarrollo de las actividades necesarias para la prevención de riesgos derivados del trabajo. Dicho riesgo laboral es definido en el art. 4.2 como «la posibilidad de que un trabajador sufra un determinado daño derivado del trabajo». Así, al ser el mobbing un fenómeno que puede generar daños y lesiones en el trabajo, la víctima puede encontrar amparo en esta norma, al tratarse dicha conducta de un riesgo laboral. Por último, los arts. 14 y 15 de esta Ley establecen un deber para el empresario

${ }^{20}$ Real Decreto Legislativo 2/2015, de 23 de octubre, por el que se aprueba el texto refundido de la Ley del Estatuto de los Trabajadores. 
de garantizar la seguridad y salud de sus trabajadores, así como tomar las medidas de prevención necesarias para evitar dichos riesgos.

Asimismo, otras normas ofrecen una definición de acoso, como en el caso de la Ley 51/2003, de 2 de diciembre, de Igualdad de Oportunidades, no Discriminación y Accesibilidad Universal de las Personas con Discapacidad, que en su art. 7 se refiere al acoso como «toda conducta relacionada con la discapacidad de una persona, que tenga como objetivo o consecuencia atentar contra su dignidad o crear un entorno intimidatorio, hostil, degradante, humillante u ofensivo» ${ }^{21}$. Igualmente, la Ley 62/2003, de 30 de diciembre, de Medidas Fiscales, Administrativas y de Orden Social ${ }^{22}$, proporciona una definición en su art. 28.d) de acoso como: «Toda conducta no deseada relacionada con el origen racial o étnico, la religión o convicciones, la discapacidad, la edad o la orientación sexual de una persona, que tenga como objetivo o consecuencia atentar contra su dignidad y crear un entorno intimidatorio, humillante $\mathrm{u}$ ofensivo».

Finalmente, existen instrumentos sin carácter de ley que tratan este tema desde diferentes perspectivas. Sin ánimo de ser exhaustivos destacamos el Criterio Técnico 69/2009, sobre las actuaciones de la Inspección de Trabajo y Seguridad Social en materia de acoso y violencia en el trabajo. Dicho Criterio sirve de guía para los miembros de la Inspección de Trabajo, proporcionando definiciones para las conductas de acoso y violencia en el trabajo, y los subtipos en los que ambos se dividen, así como las infracciones en las que incurrirían los sujetos responsables.

Asimismo, la Nota Técnica de Prevención núm. 476, de 1998, del Instituto Nacional de Seguridad e Higiene en el Trabajo, define el mobbing como la situación en la que una persona o un grupo de personas ejercen una violencia psicológica extrema (en una o más de las 45 formas o comportamientos descritos por el «Leymann Inventory of Psychological Terrorization»), de forma sistemática (al menos una vez por semana), durante un tiempo prolongado (más de seis meses), sobre otra persona en el lugar de trabajo, pudiendo traducirse dicho término al castellano como «psicoterror laboral» $\mathrm{y}$ «hostigamiento psicológico en el trabajo» ${ }^{23}$. Ofrece, ade-

${ }^{21}$ H. I. Arbonés Lapena, Acoso moral en el trabajo y su tutela preventiva, 1. ${ }^{a}$ ed., Albacete, Bomarzo, 2014, p. 25.

${ }_{22}$ Mediante la cual se incorporaron a nuestro ordenamiento las Directivas 2000/43/CE y 2000/78/CE.

${ }^{23}$ El impacto sobre la víctima, según esta nota técnica, puede ser de carácter psíquico (ansiedad, trastornos emocionales...), físico (patologías psicosomáticas) o social (hipersensibilidad a las críticas). Vid. P. Rivas VAlLejo, La prevención de los riesgos laborales de carácter psicosocial, 1. ${ }^{a}$ ed., Granada, Comares, 2008, p. 19. 
más, una descripción de las fases en que se desarrolla dicho proceso: fase de conflicto, fase de estigmatización, fase de intervención de la empresa o dirección y fase de marginación o exclusión de la vida laboral.

\section{ELEMENTOS CONSTITUTIVOS DEL ACOSO MORAL EN EL TRABAJO Y SU REFLEJO EN LA JURISPRUDENCIA ESPAÑOLA}

$\mathrm{Al}$ no existir regulación legal laboral en que los trabajadores puedan ampararse para ver defendidos sus derechos en caso de acoso, la protección a las víctimas de estas conductas destructivas ha tenido que venir dada por los tribunales a golpe de sentencia. De esta manera, existe una amplia jurisprudencia y doctrina judicial en la materia, basada principalmente en la protección de derechos fundamentales y en la doctrina elaborada al respecto en el campo de la psicología y sociología que hemos apuntado sobre estas líneas.

Esta misión ha sido realizada principalmente por los Tribunales Superiores de Justicia de nuestro país, ya que la mayor parte de los casos que acaban llegando al Tribunal Supremo mediante recursos de casación son desestimados por falta de contradicción.

Existen unas líneas doctrinales ya definidas de determinados Tribunales Superiores de Justicia, algunas más completas que otras, sobre el concepto de mobbing o de algunos de sus elementos característicos, que pasamos a explicar a continuación.

\section{Sobre el concepto de mobbing}

$\mathrm{La}$, a nuestro juicio, más completa línea doctrinal ha sido desarrollada por el TSJ de Madrid, que puede dividirse en dos vertientes. La primera de ellas ${ }^{24}$ procede a examinar la etimología del término mobbing recurriendo

${ }^{24}$ Destacamos las siguientes sentencias: SSTSJ de Madrid, Sala de lo Social, Sección 2. ${ }^{a}$, núm. 839/2006, de 7 de noviembre (AS/2007/169); Madrid, Sala de lo Social, Sección 6. ${ }^{a}$, núm. 217/2008, de 31 de marzo (AS/2008/1652); Madrid, Sala de lo Social, Sección 1. ${ }^{a}$, núm. 356/2007, de 14 de mayo (AS/2997/2308); Madrid, Sala de lo Social, Sección 1. ${ }^{a}$, núm. 604/2007, de 27 de junio (AS/2007/3012); Madrid, Sala de lo Social, Sección 1. ${ }^{\text {, }}$, núm. 614/2007, de 27 de junio (AS/2007/3011), y Madrid, Sala de lo Social, Sección $1 .{ }^{a}$, núm. 382/2006, de 16 de mayo (AS/2006/2280), entre muchas otras. 
a la definición que del verbo acosar ofrece el Diccionario de la Real Academia de la Lengua como «la acción de perseguir, sin darle tregua ni reposo, a un animal o a una persona».

Más adelante enfatiza la importancia que implica añadir el adjetivo «moral» al término acoso, al significar ello que dicha clase de acoso tiene como finalidad el desmoronamiento íntimo y psicológico de la persona. Añade que este comportamiento ha sido objeto de un estudio pluridisciplinar en el que participan la psicología, la psiquiatría, la sociología y el derecho, y que puede generarse por sentimientos de envidia, egoísmo, celos, miedo, rivalidad y narcisismo, que generan importantes problemas de convivencia y producen lesiones psíquicas en el sujeto acosado, deteriorando así la integración en la empresa y conduciendo a casos de absentismo laboral por baja médica, que implican un trastorno en el desarrollo normal del trabajo y una carga para las arcas de la Seguridad Social. Por último, con respecto a las definiciones que de acoso moral ofrece el Derecho comunitario, explica que en el mismo no se requiere una reiteración de la conducta ni que exista una intencionalidad en la misma para ser considerada constitutiva de acoso, sino que basta con que se hay producido un ataque contra la dignidad de la persona.

La segunda línea del TSJ de Madrid entiende el mobbing como una forma característica de estrés laboral que se produce a raíz de las relaciones interpersonales existentes en el centro de trabajo, donde la parte hostigadora tiene más recursos, apoyos o posición superior a la del trabajador afectado, el cual percibe la intención de aquellos de causarle daño o mal. Esta situación acaba siendo especialmente estresante, sin que el trabajador acosado sepa cómo afrontarla para poder modificarla ni cómo controlar las reacciones emocionales que le produce dicho proceso. El fracaso en este afrontamiento y en el control de la ansiedad desencadena una patología propia del estrés, que se va cronificando y agravando progresivamente ${ }^{25}$.

${ }^{25}$ En este sentido destacamos, sin ánimo de exhaustividad, las siguientes sentencias: SSTSJ de Madrid, Sala de lo Social, Sección 1. ${ }^{a}$, núm. 278/2004, de 30 de marzo (AS/2004/2929); Madrid, Sala de lo Social, Sección 1. ${ }^{a}$, núm. 931/2007, de 21 de noviembre (AS/2008/380); Madrid, Sala de lo Social, Sección 1. ${ }^{a}$, núm. 791/2004, de 14 de septiembre (AS/2004/2755); Madrid, Sala de lo Social, Sección 1. ${ }^{a}$, núm. 634/2004, de 22 de junio (AS/2004/2480); Madrid, Sala de lo Social, Sección 1. ${ }^{a}$, núm. 936/2007, de 21 de noviembre (JUR/2008/44779); Madrid, Sala de lo Social, Sección 1. ${ }^{a}$, núm. 292/2010, de 20 de abril (JUR/2010/233251), y Madrid, Sala de lo Social, Sección 1. ${ }^{a}$, núm. 1109/2007, de 27 de diciembre (JUR/2008/100587). 
Por otra parte, el TSJ de Galicia ${ }^{26}$ se refiere en varias de sus sentencias al mobbing como conducta abusiva o violencia psicológica a la que se somete de forma sistemática a una persona en el ámbito laboral, y que se manifiesta especialmente a través de reiterados comportamientos, palabras $\mathrm{o}$ actitudes que lesionan la dignidad o integridad psíquica del trabajador y que ponen en peligro o degradan sus condiciones de trabajo. Según el tribunal, dichas actitudes de hostigamiento conducen al aislamiento del acosado en el marco laboral, generándole cuadros de ansiedad, estrés, pérdida de autoestima y alteraciones psicosomáticas, concluyendo en algunos casos con el abandono de su empleo al resultar insostenible la presión a que se encuentra sometido. Finalmente, entiende que se trata de una forma de estrés laboral que se caracteriza por tener su origen en las relaciones interpersonales que se producen en el seno de la empresa. Esta definición ha sido empleada por otros Tribunales Superiores de Justicia como, por ejemplo, el de Cataluña en reiteradas ocasiones ${ }^{27}$.

Otros tribunales ofrecen la definición de mobbing proporcionada por Heinz Leymann, tal como el TSJ de Galicia ${ }^{28}$ o el de Castilla-La Mancha ${ }^{29}$.

Asimismo, varios Tribunales Superiores de Justicia (tales como Canarias, Castilla-La Mancha, Galicia, Madrid y País Vasco) recogen una línea que resume los intentos de acotar el concepto de mobbing en tres: a) fenó-

${ }^{26}$ Destacamos, entre otras, las siguientes sentencias: SSTSJ de Galicia, Sala de lo Social, Sección 1. ${ }^{a}$, núm. 135/2012, de 23 de diciembre (AS/2012/85); Galicia, Sala de lo Social, Sección 1. ${ }^{2}$, núm. 5859/2010, de 17 de diciembre (AS/2011/97); Galicia, Sala de lo Social, Sección 1. ${ }^{\text {, }}$ núm. 5657/2010, de 7 de diciembre (AS/2011/148); Galicia, Sala de lo Social, Sección 1. a, núm. 4401/2010, de 15 de octubre (AS/2010/2565); Galicia, Sala de lo Social, Sección 1. a , núm. 386/2010, de 25 de enero (AS/2010/892), y Galicia, Sala de lo Social, Sección 1. ${ }^{a}$, núm. 5330/2009, de 26 de noviembre (AS/2009/2648).

${ }^{27}$ En este sentido, recogemos las siguientes sentencias: SSTSJ de Cataluña, Sala de lo Social, Sección 1. ${ }^{\text {, }}$, núm. 4800/2006, de 23 de junio (AS 2007/211); Cataluña, Sala de lo Social, Sección 1. ${ }^{a}$, núm. 4387/2011, de 20 de junio (AS/2011/1936); Cataluña, Sala de lo Social, Sección 1. ${ }^{a}$, núm. 3343/2010, de 6 de mayo (JUR/2010/306069); Cataluña, Sala de lo Social, Sección 1. ${ }^{a}$, núm. 8633/2010, de 21 de diciembre (JUR/2013/91991), y Cataluña, Sala de lo Social, Sección 1. ${ }^{a}$, núm. 3335/2010, de 6 de mayo (JUR/2010/306105).

${ }^{28}$ SSTSJ de Galicia, Sala de lo Social, Sección $1 .^{a}$, núm. 855/2008, de 3 de marzo (AS/2008/1125); Galicia, Sala de lo Social, Sección 1. ${ }^{a}$, de 27 de enero de 2005 (AS/2005/268); Galicia, Sala de lo Social, Sección 1. ${ }^{a}$, núm. 4451/2010, de 4 de octubre (AS/2010/2515), y Galicia, Sala de lo Social, Sección 1. ${ }^{\text {, }}$, de 30 de octubre de 2003 (JUR/2004/56870), entre otras.

29 SSTSJ de Castilla-La Mancha, Sala de lo Social, Sección 1. a , núm. 1532/2008, de 15 de octubre (AS/2008/2657); Castilla-La Mancha, Sala de lo Social, Sección 1. ${ }^{\text {a }}$, núm. 423/2006, de 9 de marzo (AS/2006/898); Castilla-La Mancha, Sala de lo Social, Sección 1. ${ }^{a}$, núm. 1285/2005, de 13 de octubre (AS/2005/3125), y Castilla-La Mancha, Sala de lo Social, Sección $1 .^{\text {a }}$, núm. 777/2008, de 15 de mayo (JUR/2008/355967), entre otras. 
meno en el que una persona o grupo ejercen una violencia psicológica extrema, sistemática y durante un tiempo prolongado sobre otra en el lugar de trabajo con la finalidad de destruirlo; $b$ ) el ofrecido por la Comisión Europea el 14 de mayo de 2001, y c) el definido jurídicamente como presión laboral tendente a la autoeliminación de un trabajador.

Muy reveladora resulta también la definición proporcionada de manera reiterada por el TSJ de Aragón ${ }^{30}$ del acoso moral como una agresión del empresario, o de sus empleados con el conocimiento y tolerancia de aquél, mediante hechos, órdenes o palabras, repetida y duradera en el tiempo, teniendo como fin el descrédito y el aislamiento del trabajador, produciéndose incluso daños en su salud y así conseguir que abandone su puesto. Se produce un daño progresivo y continuo a su dignidad, dependiendo la resistencia del trabajador hacia esta actitud de su fortaleza psicológica. Entiende que existe un ánimo del acosador de victimizar al trabajador, hasta producirle una sensación de que es inútil o indeseable, siendo esta finalidad de victimización lo fundamental en esta línea doctrinal tanto en los casos de mobbing como en los de bossing ${ }^{31}$ o en los de bullying, siendo por otra parte necesario también que la ejecución de esta conducta se realice de manera grupal.

De otro lado, el TSJ de Navarra ${ }^{32}$ recoge una serie de conductas como constitutivas de mobbing que serían: «1) Ataques mediante medidas adoptadas contra la víctima: el superior le limita las posibilidades de comunicarse, le cambia la ubicación separándole de sus compañeros, se juzga de manera ofensiva su trabajo, se cuestionan sus decisiones. 2) Ataque mediante aislamiento social. 3) Ataques a la vida privada. 4) Agresiones verbales, como gritar o insultar, criticar permanentemente el trabajo de esa persona. 5) Rumores: criticar y difundir rumores contra esa persona».

Por último, el TSJ de Asturias matiza la diferencia entre mobbing y hostigamiento psicológico o acoso moral. Considera el primero como un maltrato persistente, deliberado y sistemático, realizado por varios miembros de una organización hacia un individuo con la finalidad de aniquilarlo y eliminarlo de dicha organización, mientras que el segundo se tra-

30 SSTSJ de Aragón, Sala de lo Social, núm. 317/2012, de 13 de junio, (AS/2012/1925); Aragón, Sala de lo Social, núm. 583/2013, de 27 de noviembre, (AS/2014/182); Aragón, Sala de lo Social, núm. 443/2012, de 18 de julio (AS/2012/2849), y Aragón, Sala de lo Social, núm. 521/2010, de 7 de julio, (AS/2011/430), entre otras.

31 Acoso vertical descendente.

32 SSTSJ de Navarra, Sala de lo Social, núm. 161/2001, de 18 de mayo (AS/2001/1824); Navarra, Sala de lo Social, núm. 394/2002, de 18 de mayo, (AS/2003/679), y Navarra, Sala de lo Social, núm. 399/2002, de 24 de diciembre (AS/2003/681). 
taría de un comportamiento reiterado y constante de violencia psíquica ejercida por alguien con una posición jurídica dominante que se considera amenazado por la víctima de su agresión, por lo que intenta destruirla para reforzar su posición ${ }^{33}$.

\section{ELEMENTOS DEL ACOSO MORAL EN EL TRABAJO}

A continuación vamos a examinar los elementos característicos del acoso moral en el trabajo que hemos señalado anteriormente, sin profundizar, tras las investigaciones de autores de los campos de la psicología, la psiquiatría y la sociología que, cómo veremos más adelante, han sido imprescindibles para la elaboración de la doctrina judicial ${ }^{34}$ que sobre esta materia existe hoy en nuestro país.

\section{Desigualdad de poder entre los sujetos activo y pasivo}

En primer lugar, en el seno de la empresa, el acoso nace de una confrontación en términos de desigualdad y se manifiesta como un abuso producto de una situación de superioridad de cualquier tipo. Se puede hablar de diferentes posiciones dentro de la escala jerárquica en la que un superior jerárquico aplasta con su poder a su subordinado. Es un caso muy habitual, como expresa Marie-France Hirigoyen: «Con frecuencia, el "jefecillo" se revaloriza de esta manera. Para compensar la fragilidad de su identidad, necesita dominar, y lo hace tanto más fácilmente cuanto que su subordinado, temiendo el despido, no tienen otra opción que la de padecer su dominio» ${ }^{35}$. Esta situación se ve, por tanto, reforzada en periodos de crisis económica, en las que el trabajador prefiere soportar la situación

33 SSTSJ de Asturias, Sala de lo Social, núm. 3219/2008, de 24 de octubre, (AS/2008/2701); Asturias, Sala de lo Social, núm. 290/2012, de 27 de enero (AS/2012/182), y Asturias, Sala de lo Social, núm. 2979/2010, de 3 de diciembre (AS/2011/204), entre otras.

${ }^{34}$ Recoge de manera clara y exhaustiva los elementos del mobbing la doctrina judicial sentada por la Sala de lo Social del TSJ de Aragón en Sentencias como la de su Sección $1 .{ }^{a}$, núm. 521/2010, de 7 de julio (AS/2011/430); núm. 317/2012, de 13 de junio (AS/2012/1925); núm. 583/2013, de 27 de noviembre (AS/2014/182); núm. 443/2012, de 18 de julio (AS/2012/2849); núm. 838/2008, de 3 de noviembre (AS/2009/518), y núm. 205/2006, de 28 de febrero (AS/2006/1618).

${ }_{35}$ M. F. HiRigoyen, El acoso moral. El maltrato psicológico en la vida cotidiana, Barcelona, Paidós Contextos, 1999, p. 60. 
de abuso antes que abandonar el puesto de trabajo o poner dicha situación en conocimiento de la autoridad pertinente por miedo a no encontrar un nuevo empleo. Sin embargo, el acoso no solo se produce por una situación de superioridad jerárquica, sino de cualquier otra índole — como, por ejemplo, física - o una mejor relación con el resto de compañeros de la empresa que otorga de facto al acosador un estatus superior.

De esta manera, el mobbing puede ser horizontal, entre compañeros de trabajo, o vertical, que se subdivide a su vez en vertical descendente (de un superior jerárquico a un subordinado) y en vertical ascendente (de un subordinado a un superior jerárquico).

Sobre este elemento se han pronunciado diferentes tribunales en sus sentencias. Por ejemplo, la Sentencia del TSJ de Canarias núm. 635/2003, de 28 de abril (AS/2003/3894), afirma que entre el sujeto activo (acosador) y el pasivo (víctima de acoso) debe existir una relación asimétrica de poder, ya sea por la posición jerárquica o por cualquier otra razón, como una mayor influencia sobre el resto de compañeros.

También es importante determinar la responsabilidad de los sujetos activos: si tan solo debe responder el acosador por su comportamiento o también debe hacerlo su superior jerárquico o la empresa por haberlo tolerado o no haber adoptado las medidas de protección oportunas. En la Sentencia del Tribunal Superior de Justicia de Canarias, Sala de lo Social, Sección 1. ${ }^{a}$, núm. 695/2013, de 4 de noviembre (JUR/2014/117313), se distribuye la responsabilidad entre los compañeros de trabajo que acosaban a la víctima y los superiores jerárquicos que lo permitieron sin llevar a cabo las medidas oportunas para evitarlo. Dicha distribución se realiza tanto en los daños morales como en los patrimoniales. Del mismo modo deberán depurarse las correspondientes responsabilidades en caso de que el mobbing se produzca con la intervención de una Empresa de Trabajo Temporal (ETT).

Otra cuestión debatida con respecto a los sujetos del acoso es si los acosadores deben formar parte ineludible del tejido empresarial o si pueden ser terceros ajenos a la empresa, como clientes, pacientes, alumnos, etcétera.

En nuestro país no se han registrado muchos casos al respecto y en los que se han producido la respuesta ha sido favorable a la integración en la empresa, puesto que, en caso contrario, se trataría de otros fenómenos o riesgos psicosociales, como el burnout o el estrés profesional. Así se recoge en la Sentencia del TSJ de Galicia de 16 de enero de 2004 (AS72004/631), en la que eran los miembros del APA (Asociación de Padres de Alumnos) quienes hostigaban a dos empleadas de un centro de enseñanza. No habría 
sido considerado mobbing de no ser porque miembros de la dirección del colegio se vieron implicados en la práctica de dicha conducta.

En mi opinión, este concepto debe ser ampliado, sin que deba ser estrictamente necesario que el sujeto forme parte de la empresa, sino que también puede realizarse por sujetos externos. Se trata de una idea íntimamente relacionada con otro elemento del mobbing que veremos a continuación, la reiteración de la conducta en el tiempo. Existen colectivos, como los pacientes de un hospital o los alumnos de un colegio, instituto o universidad, que pasan más tiempo con los médicos, enfermeras, profesores o personal docente que con sus propios compañeros de profesión. Es por ello que pueden adoptar comportamientos hostigadores reiterados durante largos periodos de tiempo, de la misma manera que en los casos de mobbing entre compañeros de trabajo. De hecho, las profesiones sanitarias o educativas forman parte de las más sometidas a estrés y acoso laboral.

La responsabilidad en estos casos se dividiría de la siguiente manera: por una parte, el acosador, al no formar parte de la empresa, podría ser castigado por un delito de acoso no laboral o laboral en el caso de incluir a estos sujetos en la legislación. Asimismo, la empresa sería responsable por haber tolerado la existencia de estos comportamientos en su seno sin haber tomado las medidas oportunas para evitarlo o castigarlo.

Sobre esta cuestión se han desarrollado directrices multisectoriales para solucionar la violencia y el acoso de terceros relacionados con el trabajo firmadas por FSESP, UNI-Europa, CSEE, HOSPEEM, CMRE, EFEE, EuroCommerce y CoESS el 16 de julio de 2010. Su objetivo es garantizar políticas con medidas prácticas en los lugares de trabajo que puedan adoptar los empleadores, trabajadores y sus representantes y sindicatos para reducir y prevenir dichas conductas. Ello se relaciona con la obligación (recogida a nivel europeo y nacional) de empresarios de garantizar la seguridad y salud de sus trabajadores en todos los aspectos relacionados con el trabajo, así como de los propios trabajadores de cuidar su propia seguridad y salud en la medida de los posible, y la de otras personas afectadas por sus acciones en el trabajo.

Según estas directrices, los interlocutores sociales encuentran cada vez más preocupante esta cuestión, ya que la violencia de terceros sobre los trabajadores conlleva un grave impacto económico, de absentismo laboral y de generación de un ambiente de trabajo inseguro, también para el resto del público y usuarios. Consideran necesario establecer un marco de pre- 
vención y de gestión del acoso que los empleadores deben desarrollar, previa consulta a sus trabajadores y representantes ${ }^{36}$.

\section{Dignidad como bien jurídico protegido}

La conducta acosadora puede vulnerar diferentes derechos de la víctima, es decir, es un comportamiento pluriofensivo ${ }^{37}$, resultando, para algunos autores, siempre atacadas, la dignidad y la integridad del trabajador ${ }^{38}$ (arts. 10 y $15 \mathrm{CE})^{39}$, debiendo ambos derechos ser puestos en relación ${ }^{40}$. Puede entenderse como una cuestión de intensidad y alcance para diferenciar el mobbing de otras figuras diferentes (estrés o burnout), en las que no se produce esta vulneración de derechos, o no de una manera tan grave.

$\mathrm{El}$ ataque a la dignidad de la persona en el mobbing se produce a través de insultos, vejaciones, rumores, etc. No se debe efectuar un listado exhaustivo de los comportamientos que pueden ser considerados acoso, puesto que acabaría resultando ineficaz e incompleto ${ }^{41}$. Asimismo, otros derechos pueden verse atacados con una conducta de acoso moral, tales como el principio de igualdad y no discriminación (recogido en el art. 14 CE) ${ }^{42}$ y el derecho al honor cuando, por ejemplo, las descalificaciones o

36 J. GarCía Viña, «La incidencia del Acuerdo Marco Europeo sobre Acoso y Violencia en el Trabajo», 2013, pp. 6-8, disponible en bttp://islssl.org/wp-content/uploads/2013/03/ Spain-Laincidencia-Vina.pdf.

37 STSJ de Madrid, Sala de lo Social, Sección 1. ${ }^{a}$, núm. 41/2008, de 21 de enero.

38 S. PÉrez Agulla, «Doctrina de suplicación sobre el acoso laboral», Revista española de Derecho del Trabajo, núm. 158 (2013), p. 4.

${ }^{39} \mathrm{La}$ dignidad se contempla en este caso desde dos perspectivas: constitucional (art. $10 \mathrm{CE}$ ) y profesional [destinada a preservar los intereses del trabajador no tanto como persona, sino como prestador de servicios, en base al art. 4.2.e) del Texto Refundido del Estatuto de los Trabajadores].

${ }^{40}$ Dicha relación ya ha sido puesta de manifiesto por el TC y la jurisprudencia penal, estableciendo el TS en su Sentencia 588/2000, de 6 de abril (RJ/2000/3438), la defensa de la integridad moral como manifestación directa de la dignidad humana que comprende tanto las facetas de la personalidad como las de la identidad individual, el equilibrio psicofísico, la autoestima o el respeto ajeno que debe acompañar a todo ser humano.

${ }^{41}$ Heinz Leymann elaboró una lista de cuarenta y cinco conductas hostiles agrupadas en cinco categorías: impedir que la víctima se exprese, aislar a la víctima, menospreciar a la víctima delante de colegas, desacreditar el trabajo de la víctima y comprometer la salud de la víctima. Por su parte, Marie-France Hirigoyen las divide en: aislamiento y negativa a la comunicación, atentado contra las condiciones de trabajo y ataques personales e intimidaciones.

42 Distinguiéndose el acoso moral del acoso discriminatorio, ya que este último requiere la presencia de un elemento grupal, esto es, la víctima es acosada por su pertenencia a un determinado grupo, ya sea etnia, religión, etcétera. 
decisiones empresariales ponen en tela de juicio la competencia del trabajador y su prestigio profesional ${ }^{43}$. También puede verse afectado el derecho a la libertad de expresión ${ }^{44}$ o a la intimidad, a la libertad ideológica (art. 16 CE) y el derecho a la tutela judicial efectiva (art. 24 CE), relacionada especialmente con la «garantía de indemnidad» que ampara al trabajador ante las consecuencias perjudiciales que para el ámbito de sus relaciones privadas o públicas se puedan derivar del ejercicio de sus derechos.

\section{Reiteración de la conducta hostigadora durante un periodo de tiempo}

Dichos ataques a los derechos del trabajador deben producirse con una cierta reiteración a lo largo del tiempo, llegando así al tercer elemento fundamental en el mobbing. Según la Sentencia del TSJ de Madrid, Sala de lo Social, Sección 1. a, núm. 41/2008, de 21 de enero (AS/2008/947), es elemento caracterizador del mobbing la sistematicidad, reiteración y frecuencia de la presión psicológica ejercida sobre una persona. Esta misma sentencia afirma que el requisito de la duración de la conducta en el tiempo (así como el de la intencionalidad) se suaviza en el Derecho comunitario (Directivas 2000/43, 2000/78 y 2002/73), debiendo determinar la misma el intérprete en cada supuesto concreto. Por otra parte, la Sentencia del Tribunal Superior de Justicia de Canarias, Sala de lo Social, Sección Única, núm. 635/2003, de 28 de abril (AS/2003/3894), hace referencia al periodo de tiempo en que es necesario que se produzca esta conducta y a la reiteración de esta, mencionando la definición proporcionada por $\mathrm{H}$. Leymann de mobbing, según la cual se trataría de «aquella situación en la que una persona o grupo ejercen una violencia psicológica extrema de forma sistemática y recurrente (como media una vez por semana) y durante un tiempo prolongado (como media seis meses) sobre otra persona» ${ }^{45}$.

43 STC 180/1999, de 11 de octubre (RTC/1999/180): «La actividad profesional suele ser una de las formas más destacadas de manifestación externa de la personalidad y de la relación del individuo con el resto de la colectividad, de forma que la descalificación injuriosa o innecesaria de ese comportamiento tiene un especial e intenso efecto sobre dicha relación y sobre lo que los demás puedan pensar de una persona, repercutiendo tanto en los resultados patrimoniales de su actividad como en la imagen personal que de ella se tenga».

${ }^{44}$ STSJ de Cataluña, Sala de lo Social, Sección 1. ${ }^{a}$, núm. 5761/2001, de 17 de julio (AS/2009/1881).

${ }^{45}$ En ese sentido se pronuncia la Sentencia del TSJ de Castilla-La Mancha, Sala de lo Social, Sección $1{ }^{\text {a }}$, núm. 421/2012, de 10 de abril. 
Como podemos comprobar, no existe acuerdo con respecto al número de veces que deben realizarse los comportamientos hostiles ni el intervalo de tiempo mínimo para ello.

Por ejemplo, El Tribunal Superior de Justicia de Andalucía en su Sentencia 4814/2002, de 19 de diciembre (AS/2003/891), considera que la conducta enjuiciada en ese supuesto era constitutiva de mobbing, dada la gran proximidad en el tiempo de los comportamientos, aunque estos se produjeran tan solo en el transcurso de un mes. Esta situación suele comenzar con pequeños ataques al principio, apenas perceptibles, o con la difusión de rumores malintencionados, por lo que situar el inicio de la conducta hostigadora en el tiempo es una tarea ardua. Establecer un límite temporal para considerar que una conducta es constitutiva de mobbing es una cuestión peligrosa, ya que pueden quedar sin protección legal diferentes situaciones en las que efectivamente se está produciendo un comportamiento acosador. Asimismo, la protección del riesgo llevada a cabo por el Tribunal Constitucional entiende que no debe esperarse a la producción efectiva de un daño o lesión, sino que basta con acreditar la existencia de un riesgo relevante de que suceda dicho daño, puesto que, en caso contrario, la tutela constitucional supondría una protección ineficaz ex post ${ }^{46}$. Entiendo que, una vez se está produciendo una conducta acosadora, no debe esperarse a que sea demasiado grave e irreversible para denunciarla.

Por todo ello y en mi opinión, la cuestión de la reiteración en el tiempo debe quedar esbozada de manera genérica en la norma, sin fijar un límite, y que sea labor de los tribunales considerar en cada caso si han transcurrido el tiempo y los ataques necesarios para calificar la conducta como acoso moral.

\section{Intencionalidad}

Por otra parte, es imprescindible que exista una voluntad del acosador de minar la moral de la víctima, de hundirla hasta que desee abandonar su puesto de trabajo. Este rasgo diferencia al mobbing de otros riesgos psicosociales como el estrés o el burnout ${ }^{47}$. Esta cuestión ha sido objeto de deba-

${ }^{46}$ Con referencia a una protección constitucional basada en la existencia de un riesgo de daño destaca la STC núm. 221/2002, de 25 de noviembre (RTC/2002/221), así como la STC, Sala Primera, núm. 220/2005, de 12 de septiembre (RTC/2005/220).

${ }^{47}$ Se trata de la última fase del estrés, caracterizada por un agotamiento físico y psicológico absoluto, producido por la implicación a largo plazo en situaciones profesionales de elevado nivel de exigencia. 
te, puesto que diferentes autores consideran más importante fijarse en los efectos que se han producido en la víctima que en la intención del acosador. Esta es la postura que han adoptado, por ejemplo, los tribunales franceses, que reconocen el acoso moral «involuntario» ${ }^{48}$.

Por mi parte, considero que es necesario un elemento volitivo, un deseo de perjudicar a la víctima, motivado por cualquier causa (envidia, frustración o psicopatía), sin el cual el comportamiento no supondría un acoso, sino unas prácticas empresariales despóticas que podrían verse castigadas por incumplir el empresario con su deber de salvaguardar la seguridad y salud de sus trabajadores.

\section{Efectos del acoso moral en la víctima}

Un sector de la doctrina y de la jurisprudencia (especialmente la más antigua) considera necesaria la producción de un daño en la víctima, físico o psicológico, para poder considerar la conducta como constitutiva de acoso moral. Sin embargo, el sector mayoritario infiere que no lo entiende como un elemento indispensable, considerando que las reacciones frente a una misma conducta varían sustancialmente de unas personas a otras, por lo que, de ser necesaria la existencia de un daño en el acosado, se perjudicaría gravemente a aquellos que presenten una mayor fortaleza física y psicológica. Entiendo mucho más lógica esta última postura, puesto que la conducta debe ser estudiada de manera objetiva, es reprochable e ilícita con independencia del resultado que provoque en la víctima de acoso. Por tanto, no se trataría de un elemento indispensable del mobbing, a pesar de que en la mayoría de los casos se producen efectos adversos en la salud de la víctima (y permite diferenciar el acoso laboral del Derecho del Trabajo del delito recogido en el Código Penal, que se refiere a los casos más graves de mobbing).

\section{CONCLUSIONES: POSIBLES SOLUCIONES A LA PROBLEMÁTICA DEL ACOSO MORAL EN EL TRABAJO EN NUESTRO PAÍS}

Tras haber realizado en este trabajo de investigación un estudio sobre el mobbing desde la perspectiva de la psicología, la psiquiatría y la sociolo-

${ }^{48}$ M. F. Hirigoyen, Todo lo que hay que saber.., op. cit., p. 31. 
gía, de las respuestas normativas proporcionadas tanto en el terreno internacional como en el comunitario o nacional, así como la respuesta ofrecida por los tribunales españoles ante la falta de legislación específica, podemos llegar a las siguientes conclusiones:

En primer lugar, los casos de acoso moral en el trabajo en España no cuentan con una ley acorde a la gravedad del problema que permita a los tribunales actuar con cierta seguridad y ofrecer una protección efectiva a las víctimas del mismo. De esta manera, los tribunales han tenido que basar sus decisiones en teorías propias del campo de la psicología, así como en doctrina y jurisprudencia relativa a derechos fundamentales. Debido a esto se han desarrollado algunas líneas de doctrina judicial muy completas en la materia en algunos tribunales, pero no en otros, por lo que la respuesta a las víctimas es desigual en función del tribunal.

Teniendo en cuenta la falta de una directiva comunitaria en materia de acoso moral en el trabajo y la negativa de algunos sectores a promulgar una ley al respecto hasta que aquella se publique, los tribunales españoles se verán obligados a continuar su labor como venían haciendo hasta ahora, sin poder ampararse en una normativa eficaz e igual para todos.

Finalmente, y en mi opinión, como solución más razonable creo necesario desarrollar una serie de preceptos en una ley (o en un apartado dentro del Estatuto de los Trabajadores) que contenga una definición del concepto de acoso en el trabajo amplia y general, dado que, en el caso de ser demasiado restrictiva, privaría de protección determinados supuestos que hoy en día sí se ven amparados por los tribunales. Dicha normativa ofrecería a los tribunales un marco legal en el que basar sus decisiones, dejando siempre un margen a su interpretación en aquellas cuestiones que no deben ser tasadas legalmente para evitar dejar sin protección determinadas situaciones de acoso (tal es el caso de la determinación del periodo de tiempo en el que deben producirse los ataques a la dignidad del trabajador o la reiteración de estos, entre otras cuestiones). Esta es la determinación que tomó Francia hace algunos años, sin esperar a la redacción de una directiva, con el fin de ofrecer una regulación legal de protección a los trabajadores. 


\section{BIBLIOGRAFÍA}

Arbonés Lapena, H. I., Acoso moral en el trabajo y su tutela preventiva, 1. ${ }^{\text {a ed., }}$ Albacete, Bomarzo, 2014.

Cavas Martínez, F., «Un nuevo supuesto de extinción causal del contrato de trabajo por acoso laboral», Revista Doctrinal Aranzadi Social, vol. 6, núm. 5 (2013), pp. 253-260.

GarCíA ViÑA, J., «La incidencia del Acuerdo Marco Europeo sobre Acoso y Violencia en el Trabajo», 2013, disponible en http://islssl.org/wp-content/ uploads/2013/03/Spain-Laincidencia-Vina.pdf.

Hirigoyen, M. F., El acoso moral. El maltrato psicológico en la vida cotidiana, Barcelona, Paidós Contextos, 1999.

- Todo lo que hay que saber sobre el acoso moral en el trabajo, Barcelona, Paidós Contextos, 2014,

Martínez Atienza, G., Tratamiento jurídico-criminológico del mobbing o acoso laboral, Barcelona, Vlex, 2011.

Pérez Agulla, S., «Doctrina de suplicación sobre el acoso laboral», Revista española de Derecho del Trabajo, núm. 158 (2013), pp. 281-297.

Pérez Machío, A. I., Mobbing y Derecho penal, 1. a ed., Valencia, Tirant lo Blanch, 2007.

Rivas Vallejo, P., La prevención de los riesgos laborales de carácter psicosocial, 1. ${ }^{\text {a }}$ ed., Granada, Comares, 2008.

bttps://www.eurofound.europa.eu/es/surveys/european-working-conditions-surveys/ fifth-european-working-conditions-survey-2010

bttps://www.eurofound.europa.eu/es/data/european-working-conditions-survey. 